\title{
Impact of Transformational Leadership Intervention on Head Nurses Working in Government Hospital
}

\author{
KHUDIJA MUSHTAQ ${ }^{1}$, MUHAMMAD HUSSAIN², KOUSAR PARVEEN ${ }^{3}$, MUHAMMAD AFZAL $^{4}$, SADIA KHAN ${ }^{5}$, SYED AMIR \\ GILANI ${ }^{6}$ \\ ${ }^{1}$ Master of Science in Nursing, Lahore School of Nursing, The University of Lahore. \\ ${ }^{2}$ Associate Professor, Lahore School of Nursing, The University of Lahore. \\ ${ }^{3}$ Assistant Professor, Lahore School of Nursing, The University of Lahore. \\ ${ }^{4}$ Associate Professor, Head of Department/Principal, Lahore School of Nursing, The University of Lahore. \\ ${ }^{5}$ Senior Lecturer Biostatistics, Faculty of Allied Health Sciences, The University of Lahore. \\ ${ }^{6}$ Dean, Allied Health Sciences, The University of Lahore \\ Correspondence to: Khudija Mushtaq, Email: khudija79@gmail.com
}

\begin{abstract}
Background: Transformational leader ship skill (TLS) plays a crucial role in hospital management and administration. Unfortunately, healthcare providers (HCPs) lack the essential awareness of transformational leadership skills (TLS). There is a dire need to adopt different strategies to improve their knowledge and skills.

Objective: To assess the improvement in the knowledge and skills about transformational leadership among head nurses after intervention of transformational leadership.

Methodology: A quasi-experimental study included 96 head nurses, designated with a multistage cluster random sampling technique. Ninety-six days of structured sessions were organized in two shifts (morning and evening). Pertinently, pre-intervention and post-intervention were organized for four months i.e. six hours per week, one hour per day.

Results: The present study showed that transformational leadership knowledge and skills have a significant impact on head nurses' performance. Insufficient pre-intervention scores of the study participants explained inadequate knowledge. After the 96 days (one hour/day) sessions, there was a highly significant improvement in the knowledge scores $88.5 \%$, and skills $\left({ }^{* * *} p \leq 0.001\right)$, df $=95$ of head nurses regarding transformational leadership. Conclusion: The currents study showed that head nurses had inadequate knowledge regarding transformational leadership. The knowledge was significantly improved after the intervention of transformational teaching and training sessions. The addition of consistent training programs in the curriculum may ensure leadership skills to enhance the quality of nursing care as well as the commitment of employees. Therefore, it is concluded that knowledge and skills are significant predictors of the head nurses' job performance.
\end{abstract}

Keywords: Transformational Leadership, Head Nurses, Knowledge, Practice, Performance

\section{INTRODUCTION}

Leader is an individual who influences for knowledge and inspires others in an encouraging way through collective communication style, using conversations, and influences strength. The concept of transformational leader is defined as the development of future vision, innovation, and stimulation of employees to accomplish organizational goals. ${ }^{1}$ Nursing managers need to improve their behaviour in government hospitals for innovation as well performance for provision of high quality of nursing care. ${ }^{2}$ A nursing leader exhibit; leadership behavior while guiding and leading nursing staff in the suitable direction. ${ }^{3}$ Transformational leadership emphasizes to generate enthusiasm for the visionary experiences to exhibit idealistic characteristic to receive respect, honour, and confidence. ${ }^{4}$ Furthermore, it is anticipated to encourage and motivate personnel to follow institutional goals and principal objectives of transformational leadership. Similarly, Transformational leaders innovate groups by leading them with further responsibilities, and improving self-reliance in them to achieve these responsibilities with confidence, dedication, and commitment. ${ }^{3}$

Transformational leadership behaviour impels a leader to work with his/her subordinates to bring necessary changes for enhancement of nursing professional performance discipline, to conduct with appropriate behaviour, and efficiency. ${ }^{5}$ According to Bednall et al.
(2017), "The effect of transformational leadership on employees during organizational change an empirical analysis" that the interventional program of transformational leadership improves individuals' behaviour, increase team cohesion and job performance. ${ }^{5}$ Transformational leadership intervention enhance nurses work engagement which effects on nurses' behaviour in favour of job performance. ${ }^{6}$

According to $\mathrm{Xu}$ (2017), the application of transformational leadership theory demonstrate positive influence on nurses' performance and also help nurses to change their behaviour as well as attitude towards their responsibilities. Transformational leadership interventional study inspires and motivates nurses. It has a significant impact on job performance, change, behaviour, and motivation. The practice of transformational leadership by nursing leaders in the clinical setting reduces stress and improve workout come so nursing leaders needs skillful training on transformational leadership behaviour. ${ }^{7}$ According to Kiran and IkramKayai (2020), Head nurses needs transformational leadership training to enhance the skills and intellectual stimulation of nursing staff. ${ }^{8}$

According to Xiao, Zhang, \&de Pablos explain the transformational leadership effect on employees' performance. It is known as a primary factor, which influence knowledge sharing of TL with staff nurses by head nurses. ${ }^{9}$ Therefore, knowledge of $T L$ is an 
intervention for head nurses which have significant impact on staff nurses' performance.

Transformational leadership has become a primary leadership style for proficiency and efficiency of nurses in any healthcare organization. According to the American Organization of Nurses Executives (AONS) reveals that transformational leadership is "the preferred leadership style for nurses, this preference is maintained by the outlook that transformational nurse leaders are the key to firming up health-systems worldwide". ${ }^{10}$ The transformational leadership is based 5Is(i.e. idealized influence, Idealized behaviour, Inspirational motivation, Intellectual stimulation and Individualized consideration). ${ }^{11}$ Firstly; idealized influence of head nurses has linked to the improvement of job performance of nurses and application of behaviour of idealized influence. ${ }^{12}$ Idealized influence demonstrates a role modeling behaviour of head nurses. Its aim is to motivate the nurses or other followers to adopt the mission and vision of leaders. ${ }^{13}$ Secondly, Idealized Behaviour means a role model for nurses or scholars. The transformational leadership program demonstrates high moral standards and ethical behavior. ${ }^{14},{ }^{15}$ Thirdly, the Inspirational Motivation is referred to as the engagement, ambition, qua the followers to visualize and work towards performance, efficiency and effectiveness. Fourthly Intellectual stimulation is creativity to encourage the followers to search for innovative ideas and then pursue those. ${ }^{14}$

Fifthly, Individualized Consideration is the training, mentoring, listening, advising and encouraging skills for the creation of positive effects. ${ }^{16}$ The models of transformational leadership programs highlight the role of the followers (staff nurses) as well as a nursing leader to increase performance throughout in an organization. ${ }^{17}$ The success of an organization is depends on effective transformational leadership programs and initiatives. The model of transformational leadership program for nurses acts to think differently and act as a role model for success. ${ }^{18}$

Transformational leadership educational program will boosts up confidence, job performance, work and conduct of nurses on the one hand and also act as motivational factor for their fresh induction in the nursing profession resulting in better service of patients in hospitals on the other hand. Furthermore, transformational leadership results in the improvement of self-respect of nurses and persuades them to play their role befittingly in the noble profession of nursing.

To the best of the researcher knowledge, this study is very first of its kind in Pakistan and no any research studies or trail is published in Pakistani context on this topic among nurses. Therefore, it will provide the platform to explore the phenomenon using quantitative research approach.

Transformational leadership intervention is sine qua non for head nurses for the improvement of knowledge and skills resulting in patient progress in Pakistan and its proper pragmatic approach would definitely promote culture of job performance. Attitudinal problem of head nurses qua their interaction and relationship with other nurses inter alia is a reason affecting their performance and ultimate sufferings of patients of government hospitals of Pakistan. The core issue of performance of transformational leadership and its effects are not properly attended and addresses in Pakistan. Scarcity of competent, diligent and hardworking head nurses is one of the causes of non-attainment of requisite standards. The government hospitals are facing multi-dimensional problems and issues. A burning issue is deterioration in performance of health care providers; therefor, transformational leadership is more and more demanding leadership style for improvement of job performance.

Regrettably, lack of strong transformational leadership is a constant issue in government hospitals which resulting in day by day deterioration of the performance of healthcare providers. In a nutshell, transformational leadership intervention among head nurses is a subject of prime importance and need of the time for achievement of positive and significant results qua job performance among nurses.

The major objective of the study was to assess the improvement of transformational leadership knowledge and skills among head nurses.

\section{MATERIAL AND METHODS}

The objective of the present study was to assess the transformational leadership knowledge and skills of head nurses in a government hospital Lahore, Pakistan. In this regard, an interventional survey was conducted to assess the knowledge and skills. A quasi-experimental study was applied. The study was conducted during the December, 2020 to July, 2021 in all in-patient departments of Services Hospital Jail Road Lahore, Pakistan

The target population of this study was comprised of 96 head nurses who were working in a government hospital of the province of Punjab while the accessible population of the study was comprised of head nurses who were working in government hospital of district Lahore. Simple random sampling technique was used to draw the sample. Sample was taken from Services hospital Lahore, Pakistan(tertiary hospital). The target population was head nurses. The sample size of96 Head Nurses was calculated with 95\% confidence level, 9\% margin of error and the expected prevalence of post adequate knowledge among Head Nurses as $71.8 \%$ taken from published study. ${ }^{3}$

Inclusion and Exclusion Criteria: Female head nurses age 25 to 60 years with 5 year experience. All diploma and degree holder head nurses who were performed in morning and evening shifts. Retired and on leave head nurses were excluded.

Research Instrument: A self-structured questionnaire was used after studying the related literature, Transformational Leadership Knowledge related Questionnaire)was applied to assess the knowledge of head nurses about transformational leadership. Questionnaire was consisted on 15 Multiple Choice Question and 05 true false questions. The second questionnaire was Multifactor Leadership Questionnaire contained three domains with three statements of each domain. This questionnaire was on liked scale.

Validity and Reliability of the Research Instrument: The reliability was done by Cronbach's Alpha coefficient test. The value of Cronbach's alpha was r 0.92.

Scoring Method: The correct answer was scored "one" mark and an incorrect answer were scored "zero". More 
than $60 \%$ knowledge was considered adequate otherwise inadequate. ${ }^{3}$ The mean score related to each component was subsequently calculated by dividing the sum of all scores by the number of items. ${ }^{3,19}$

Data Collection Procedure: Training program was 16 weeks, 1 hour per sessions, 06 days per week. Researcher was divided the head nurses into six groups $n=96(16,16$, $16,16,16,16$,$) by using instructional strategies and$ teaching methodologies. During session, presentations, role plays, and scenarios were presented for transformational leadership skills. The educational program was prepared from literatures and text book of transformational leadership. ${ }^{20}$

Data Analysis Procedure: After data collection phase, the data were tabulate, organized, and summarized. For this purpose the researcher used Statistical Package for Social Sciences (SPSS) version 25 software. For data analysis purpose, frequencies, percentages, mean, and standard deviation were used as descriptive statistics while paired samples t-test was used as inferential statistics. A value of $p$ $\leq 0.05$ was measured significant.

\section{RESULTS}

Table 1: Age of Head Nurses

\begin{tabular}{|l|l|l|}
\hline Age (Years) & $\mathrm{f}$ & $\%$ \\
\hline $25-35$ & 17 & 18 \\
\hline $36-45$ & 30 & 31 \\
\hline $46-60$ & 49 & 51 \\
\hline Total & 96 & 100 \\
\hline
\end{tabular}

Table 1 shows that $18 \%$ research participants were between the ages of 25-35 years age group. 31\% were between $35-45$ years of age group and $50 \%$ research participants were between $46-60$ years of age.

Table 2: Distribution of Research Participants with respect to Departments

\begin{tabular}{|l|l|l|}
\hline Departments & $\mathrm{f}$ & $\%$ \\
\hline CCU (Cardiac Care Unit) & 3 & 3 \\
\hline Medical unit & 10 & 11 \\
\hline Surgical unit & 10 & 11 \\
\hline Orthopedic & 4 & 4 \\
\hline Ophthalmology & 4 & 4 \\
\hline Surgical emergency & 4 & 4 \\
\hline Medical emergency & 4 & 4 \\
\hline Peads ward & 5 & 5 \\
\hline Operation theater & 18 & 19 \\
\hline KMU (Kangaroo Mother Unit) & 2 & 2 \\
\hline Surgical ICU (Intensive Care Unit) & 5 & 5 \\
\hline Medical ICU & 3 & 3 \\
\hline VVIP (Very Very Important Person) & 3 & 3 \\
\hline Neurology & 1 & 1 \\
\hline Nephrology & 1 & 1 \\
\hline Gynae Wards & 15 & 16 \\
\hline Peads emergency & 2 & 2 \\
\hline Diabetic center & 1 & 1 \\
\hline Government Officer Block & 1 & 1 \\
\hline Total & 96 & 100 \\
\hline
\end{tabular}

Table 2 shows that $3 \%$ participants belongs to CCU, $11 \%$ research participants belongs to medical, $11 \%$ belong to surgical units, $4 \%$ participants belongs to orthopedic, ophthalmology, medical and surgical wards, respectively, $4 \%$ participants belongs to peads ward, $19 \%$ participants belong to operation theater, $2 \%$ in $\mathrm{KMU}, 5 \%$ belong to surgical ICU, 3\% belong to medical ICU, 3\% belong to VVIP $1 \%$ belong to neurology, $1 \%$ belong to nephrology, $16 \%$ belong to gynae ward, $2 \%$ belong to peads emergency, $1 \%$ belong to diabetic center, and $1 \%$ belong to government officer block.

Table 3: Educational Status of Research Participants

\begin{tabular}{|l|l|l|}
\hline Educational Status & $\mathrm{f}$ & $\%$ \\
\hline General Nursing ( Diploma) & 82 & 85 \\
\hline Bachelor of Science in Nursing & 13 & 14 \\
\hline Master of Science in Nursing & 01 & 1 \\
\hline Total & 96 & 100 \\
\hline
\end{tabular}

Table 3 shows that in relation to qualification $85 \%$ head nurses have diploma holder, $14 \%$ research participants have a bachelor degree in nursing and, only $1 \%$ research participants have master degree holders.

Table 4: Experience of research participants

\begin{tabular}{|l|l|l|}
\hline Experience (years) & f & $\%$ \\
\hline $5-10$ & 8 & 9 \\
\hline $11-20$ & 27 & 28 \\
\hline $21-30$ & 56 & 58 \\
\hline $31-40$ & 5 & 5 \\
\hline Total & 96 & 100 \\
\hline
\end{tabular}

Table 4 indicates that $9 \%$ head nurses had their leadership experience between 5-10 years; likewise $28 \%$ research participants had their leadership experience between 11-20 years. 58\% head nurses had leadership experience between $21-30$ years, and only $5 \%$ research participants had 31-40 years leadership experience.

Table 5: Marital status of research participants

\begin{tabular}{|l|l|l|}
\hline Marital status & $\mathrm{f}$ & $\%$ \\
\hline Single & 15 & 16 \\
\hline Married & 80 & 83 \\
\hline Widow & 1 & 1 \\
\hline Divorced & 00 & 0 \\
\hline Total & 96 & 100 \\
\hline
\end{tabular}

Table 5 represents that $16 \%$ research participants were single, majority $83 \%$ were married, $0 \%$ participants were divorced, and $1 \%$ widow.

Table 6: Training about Transformational Leadership
\begin{tabular}{|l|l|l|}
\hline $\begin{array}{l}\text { Transformational } \\
\text { Leadership Training }\end{array}$ & $\mathrm{f}$ & $\%$ \\
\hline Yes & 3 & 3 \\
\hline No & 93 & 97 \\
\hline Total & 96 & 100 \\
\hline
\end{tabular}

Table 6 indicates that the majority $97 \%$ research participants were not trained in transformational leadership; only $3 \%$ were trained in transformational leadership.

Table 7: Teaching experience in transformational leadership

\begin{tabular}{|l|l|l|}
\hline Teaching Experience & $\mathrm{f}$ & $\%$ \\
\hline Yes & 0.0 & 0 \\
\hline No & 96 & 100 \\
\hline Total & 96 & 100 \\
\hline
\end{tabular}

Table 7 represents that $100 \%$ research participants had not the teaching experience. 
Table 8: Level of Head Nurses Knowledge about Transformational Leadership

\begin{tabular}{|l|l|l|l|l|}
\hline \multirow{2}{*}{$\begin{array}{l}\text { Transformational } \\
\text { leadership knowledge }\end{array}$} & \multicolumn{2}{|l|}{ Pre-Intervention } & \multicolumn{2}{l|}{$\begin{array}{l}\text { Post- } \\
\text { Intervention }\end{array}$} \\
\cline { 2 - 5 } & $\mathrm{f}$ & $\%$ & $\mathrm{f}$ & $\%$ \\
\hline Inadequate knowledge & 92 & 95.8 & 11 & 11.5 \\
\hline Adequate knowledge & 4 & 4.2 & 85 & 88.5 \\
\hline
\end{tabular}

As shown in Figure 1 the adequate knowledge of head nurses in pre-intervention study was $4 \%$ and inadequate knowledge was $96 \%$. While in the postintervention study there was a significant increase in adequate knowledge (88.5\%) and inadequate knowledge was decreased up to $11 \%$.

Transformational leadership knowledge among head nurses.

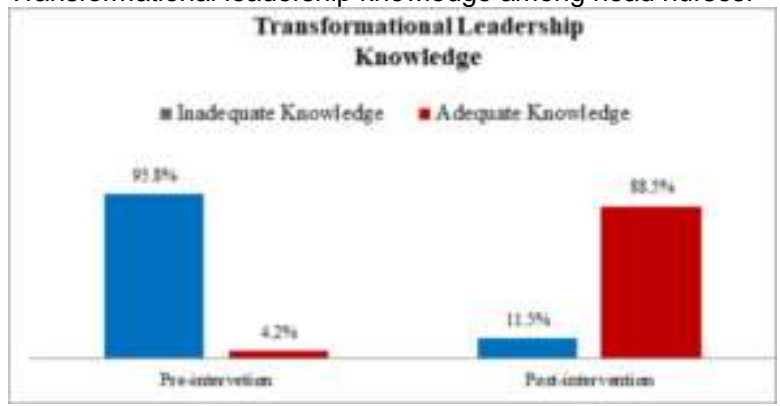

Figure 1 show that $95.8 \%$ head nurses had inadequate knowledge about transformational leadership in pre-intervention study while they had only $4.2 \%$ adequate knowledge. Knowledge was improved after the intervention $88.5 \%$ adequate knowledge and $11.5 \%$ inadequate knowledge.

Table 9: Comparison of pre-and post-intervention scores of participants

\begin{tabular}{|l|l|l|l|l|l|}
\hline $\begin{array}{l}\text { Transformation } \\
\text { al leadership }\end{array}$ & $\begin{array}{l}\text { Pre- } \\
\text { intervention }\end{array}$ & $\begin{array}{l}\text { Post- } \\
\text { intervention }\end{array}$ & \multirow{2}{*}{$\mathrm{t}$} & $\mathrm{p}$ & \multirow{2}{*}{$\eta^{2}$} \\
\cline { 2 - 7 } & Mean $\pm \mathrm{SD}$ & Mean $\pm S \mathrm{SD}$ & & & \\
\hline Knowledge & $1.04 \pm 0.201$ & $1.89 \pm 0.320$ & -22.65 & .000 & .84 \\
\hline
\end{tabular}

A very highly statistical significant difference ("* $\mathrm{P} \leq 0.001), \mathrm{df}=95$

A paired-samples t-test was conducted to evaluate the impact of the intervention on head nurses. A very highly significant mean difference was found between preintervention and post-intervention scores of head nurses on knowledge, $\mathrm{t}(95)=-22.65, \mathrm{p} \leq 0.001,\left(\eta^{2}\right)=.84$ with Mean and SD $(1.04 \pm 0.201$ vs. $1.89 \pm 0.320)$. Furthermore, the magnitude of eta squared $\left(n^{2}\right)=.84$ revealed a large effect size.

Transformational leadership skills among head nurses

\begin{tabular}{|l|l|l|l|l|l|}
\hline $\begin{array}{l}\text { Transformation } \\
\text { al leadership } \\
\text { components }\end{array}$ & $\begin{array}{l}\text { Pre- } \\
\text { intervention }\end{array}$ & $\begin{array}{l}\text { Post- } \\
\text { intervention }\end{array}$ & $\mathrm{t}$ & $\mathrm{p}$ & $\mathrm{n}^{2}$ \\
\cline { 2 - 6 } & Mean \pm SD & Mean \pm SD & & & \\
\hline $\begin{array}{l}\text { Idealized } \\
\text { Influence }\end{array}$ & $8.84 \pm 2.52$ & $12.60 \pm 1.96$ & 11.87 & .000 & .59 \\
\hline $\begin{array}{l}\text { Idealized } \\
\text { Behaviour }\end{array}$ & $8.82 \pm 2.13$ & $13.22 \pm 2.14$ & -13.07 & .000 & .64 \\
\hline $\begin{array}{l}\text { Individualized } \\
8.16 \pm 2.40\end{array}$ & Consideration & $13.20 \pm 2.63$ & -13.65 & .000 & .66 \\
\hline
\end{tabular}

A very highly statistical significant difference ("'p $p \leq 0.001)$, df $=95$

\section{DISCUSSION}

Transformational leadership is a modern leadership style. In this style visionary leaders face challenges by provocative and dare employee and take ownership of their work with wisdom. They play their role more than their performance beyond expectancy of institute is required. Therefore, transformational leadership interventional program has been accomplished for supporting head nurses to perform role of manager effectively and efficiently. . $^{3} 21$

Current study exposed that there was improvement in the knowledge of head nurses regarding transformational leadership at post-intervention program as compared to pre-intervention program. There was highly statistical difference among knowledge of head nurses. Most of the head nurses were diploma holder and they were very interested in this topic. Head nurses have ability to gain knowledge easily. The results were comparable with. ${ }^{3}$ Who conducted study "Transformational leadership educational program for head nurses and its effect on nurses' job performance" revealed that total knowledge scores of head nurses about transformational leadership were significantly improved in post-intervention compared to pre-program scores.

The Present study findings indicated that there was statistical significant improvement of mean and standard deviation in the dimensions of transformational leadership style. The dimensions include Individualized Consideration, Idealized behaviour, and Idealized influence, at postintervention than pre-intervention scores reported by head nurses.

This result was agreed with 22 in the study about "Team work effectiveness and its relationship with transformational leadership as perceived by nurses at port said general hospitals" The head nurses perform in a way that encourage dignity and present a strong role model to follow.

Present study findings showed that Individualized Consideration and idealized behaviour have the highest mean score than other dimensions and has very highest significance effect of head nurses' job performance. The role model behaviour has the greatest effect on head nurses' job performance

This study indicated that individualized consideration have lower value than other dimensions. ${ }^{23}$

Study Limitations: The study had many limitations. The study was conducted in a single hospital. There was single group with small sample size therefore, this study limit the generalizability. Only one group was evaluated. This study was limited to public hospital to improve knowledge and skills of head nurses. There could be comparison of both public and private sectors.

Acknowledgement: Thanks to Allah almighty and his beloved Prophet Hazarat Muhammad (PBUH) who gave me power and strength to write up this study. I am thankful to my principal Mr. Muhammad Afzal, supervisor (Mr. Muhammad Hussain), co-supervisor (Mrs. Kousar Parveen), and biostatistician Ms. Sadia Khan for their direction, guidance, and motivation.

\section{CONCLUSION}

On the bases of the current study findings revealed that transformational leadership intervention completed by the researcher successfully in the improvement of knowledge and skills among head nurses in the post-intervention as 
compare to pre-intervention. There was significant improvement in transformational leadership knowledge and skills of head nurses' job performance in post-intervention as compared with pre-intervention percentage, mean, and standard deviation.

Recommendations: Current study suggested the following recommendation on the bases of findings;

Organize in-service training and educational programs of transformational leadership among head nurses for refreshing and improving the knowledge and skills. Training courses of transformational leadership must be considered a prerequisite for head nurses before taking charge of her/his position. Replication of research is recommended on large sample size for more generalization. Further research studies are suggested on the impact of transformational leadership intervention of head nurses on staff nurses' job performance. Hospital administrators should arrange meetings with nurses' leaders and staff nurses to discuss different problems face by them in different departments.

Disclaimer: None

Conflict of Interest: None

Source of Funding: None

\section{REFERENCES}

1. Hoogeboom MA, Wilderom CP. Advancing the Transformational-Transactional Model of Effective Leadership: Integrating two Classic Leadership Models with a Video-Based Method. Journal of Leadership Studies 2019; 13(2): 23-46.

2. Harb B, Sidani D. Transformational leadership for organizational change in the Lebanese public sector. Problems and Perspectives in Management 2019; 17(2): 205-16.

3. Abd-Elrhaman ESA, Abd-Allah NA. Transformational Leadership Educational Program for Head Nurses and its Effect on Nurses' Job Performance. American Journal of Nursing 2018; 7(4): 127-36.

4. Yavuz M. Transformational Leadership and Authentic Leadership as Practical Implications of Positive Organizational Psychology. Handbook of Research on Positive Organizational Behavior for Improved Workplace Performance: IGI Global; 2020: 122-39.

5. Bednall TC, E. Rafferty A, Shipton H, Sanders K, J. Jackson C. Innovative behaviour: how much transformational leadership do you need? British Journal of Management 2018; 29(4): 796-816.

6. Faupel S, Süß S. The effect of transformational leadership on employees during organizational change-an empirical analysis. Journal of Change Management 2019; 19(3): 14566.

7. $\mathrm{Xu} \mathrm{J-H}$. Leadership theory in clinical practice. Chinese Nursing Research 2017; 4(4): 155-7.

8. Kiran S, IkramKayani A. Transformational Leadership As Mediating Factor Influencing Conflict Management and Performance of Teaching Faculty at Higher Education Level: AStudy in Punjab, Pakistan. Pakistan Social Sciences Review, 2020; 4(2): 272-84.
9. Xiao $\mathrm{Y}$, Zhang $\mathrm{X}$, de Pablos $\mathrm{PO}$. How does individuals' exchange orientation moderate the relationship between transformational leadership and knowledge sharing? Journal of Knowledge Management 2017; 11(3): 479-97.

10. Fischer SA. Transformational leadership in nursing: a concept analysis. Journal of advanced nursing 2016; 72(11): 2644-53.

11. Moghadam MHV, Mohammadi M, Bazaey GA. Investigating effect of transformational leadership on employees' and administrators' satisfaction of telecommunication general department of district 3 . Journal of management and accounting studies 2020; 8(2): 24-30.

12. Nyokabi SM, K'Aol GO, Njenga K. Effect of Idealized Influence and Inspirational Motivation of the CEO on Performance in the Private Sector in Kenya. American Journal of Leadership and Governance 2017; 1(2): 16-38.

13. Koveshnikov A, Ehrnrooth M. The cross-cultural variation of the effects of transformational leadership behaviors on followers' organizational identification: The case of idealized influence and individualized consideration in Finland and Russia. Management and Organization Review 2018; 14(4): 747-79.

14. Allen GP, Moore WM, Moser LR, Neill KK, Sambamoorthi U, Bell HS. The role of servant leadership and transformational leadership in academic pharmacy. American journal of pharmaceutical education 2016; 80(7): 1-7.

15. Martin J. Transformational and transactional leadership: An exploration of gender, experience, and institution type. portal: Libraries and the Academy 2015; 15(2): 331-51.

16. Broome ME, Marshall ES. Transformational Leadership: Complexity, Change, and Strategic Planning. 2020.

17. Brewer CS, Kovner CT, Djukic M, et al. Impact of transformational leadership on nurse work outcomes. Journal of advanced nursing 2016; 72(11): 2879-93.

18. Deschamps C, Rinfret N, Lagacé MC, Privé C. Transformational leadership and change: How leaders influence their followers' motivation through organizational justice. Journal of Healthcare Management 2016; 61(3): 194213.

19. Nilwala N, Gunawardana K, Fernando R. Scale for Measuring Transformational Leadership in Public Sector Organizations in Sri Lanka: With Special Reference to Ministries of Western Provincial Council. 2017.

20. Broome ME, Marshall ES. Leading Across Systems of Care and in the Larger Community. Transformational Leadership in Nursing: From Expert Clinician to Influential Leader 2020: 319.

21. To ML, Herman H, Ashkanasy NM. A multilevel model of transformational leadership, affect, and creative process behavior in work teams. The Leadership Quarterly 2015; 26(4): 543-56

22. Metwally Ibrahim FG, Elghabbour GMM. Team work effectiveness and its relation with transformational leadership as perceived by nurses at Port Said General Hospitals. Port Said Scientific Journal of Nursing 2020; 7(3): 25-41.

23. David S, Armanu A, Afnan TE. The effects of transformational leadership and personality on employee performance in Nissan Malang mediated by organizational commitment. Russian Journal of Agricultural and SocioEconomic Sciences 2017; 61(1). 